DOI: $10.14451 / 2.136 .19$

\title{
ОБ ОСОБЕННОСТЯХ ПРАВОВОГО РЕГУЛИРОВАНИЯ ДОПУСКА ИНОСТРАННЫХ ИНВЕСТОРОВ: АДМИНИСТРАТИВНО-ПРАВОВОЙ АСПЕКТ
}

\author{
(c) 2019 Казанкова Татьяна Николаевна \\ кандидат педагогических наук, доцент кафедры публичного права \\ Самарский государственный экономический университет, Россия, Самара \\ Email: tatianaok78@yandex.ru
}

В статье анализируются концепции отечественных и зарубежных исследователей относительно правовой регламентации возможностей допуска иностранных инвесторов в экономику страныреципиента. Приводятся различные модели допуска прямых иностранных инвестиций в экономику страны. В дополнение к наличествующим в юридической литературе концепциям, предлагается собственное видение определения понятия допуска инвесторов на рынок страны-реципиента.

Ключевые слова: инвестиции, страны-реципиенты, иностранные инвесторы, транснациональные компании, национальный правовой режим, прямые иностранные инвестиции.

Одним из важный факторов развития и роста современной отечественной экономики является рост иностранных инвестиций. Однако вливание иностранных инвестиций на российскую экономику не всегда имеет положительный эффект, так это может создать реальные риски потери эконмического и технологического суверенитета. В российском законодательстве предусмотрен административный регламент и механизм предварительного согласования сделок с участием иностранных инвесторов. Вместе с тем, проблема правовой регламентации допуска прямых иностранных инвестиций в отечественную экономику остается актуальной. Правовое регулирование допуска иностранных инвестиций имеет ряд отличительных черт. С точки зрения норм административного права, допуск иностранных инвесторов в экономику другого государства осуществляется с помощью применения таких правовых механизмов как запреты, дозволения и предписания, «раскрывающие исходные юридические начала административноправового регулирования...» [1]. В исследовании Дораева М.Г. на предмет инвестиционной политики государства в части допуска иностранных инвестиций в отечественную экономику с нашей точки зрения сформулированы несколько важный аспектов, таких как:

- регламентированный правовой механизм допуска иностранных инвесторов на территорию страны;

- законодательно определенный порядок самой процедуры проверки планируемых инвестиций с точки зрения непротиворечия их действующему законодательству, а так же отсутствия у них ограничений в сфере функционирования на российском рынке;

- осуществление контрольных мероприятий со стороны органов государственной власти за выполнениями иностранным инвестором всех предписаний и необходимых условий иностранных инвестиций [2].

По нашему мнению данный подход демонстрирует лишь общее представление о допуске иностранных инвестиций в экономику страны. Помимо используемых автором инструментариев так же следует выделить лицензирование, аккредитация и прочие виды согласований в случае привлечения крупных иностранных инвесторов на российский рынок. По мнению П. Фишера, использование запретительных мер в сфере привлечения иностранных инвестиций служит весомым рычагом воздействия на процесс иностранного инвестирования со стороны государства. В необходимой и достаточной совокупности механизмов его реализации он может:

- оградить от иностранных инвесторов с весомым внутренним национальным капиталом в сферы национальной экономики;

- создать необходимые барьеры для реализации возможностей транснациональных компаний в использовании своих преимуществ;

- служить надежным гарантом обеспечения национальных интересов страны и ее безопасности.

Подвергну анализу работы российский авторов на предмет различных аспектов прямых иностранных инвестиций [3], приходим к за- 
ключению о том, что отечественная наука в этом вопросе не выработала однозначной доктрины, в том числе с позиции правовых норм, что понимать буквально под термином «допуск» иностранного контента на российских рынок в целях инвестиционной деятельности. Одни исследователи под «допуском» понимают некий установленный режим дозволительных процедур, другие рассматривают допуск как некий процесс деятельности органов государственной власти, который включает в себя ряд конкретных мероприятий [4]. Наличие указанных противоречий побудила нас обратиться к опыту зарубежных государств, в целях выработки единых критериев определения допуска иностранных инвестиций на отечественный рынок.

Допуск иностранных инвестиций согласно нормам международного права опирается на принцип свободы страны-реципиента в принятии решений относительно иностранных вложений. Это его абсолютно-суверенное право одобрить или отклонить входящий поток иностранного капитала. В истории отношений подобного рода были случаи полного исключения прямых иностранных инвестиций, например Китай или СССР. В последнее время в виду жесткой конкурентной борьбы за возможность прямых иностранных инвестиций, наметился очевидный курс на политику либерализации указанной сферы правоотношений. Как показала практика, режимы, выбравшие курс на полную изоляцию экономики от иностранных инвестиций, рискуют оказаться в эконмическом вакууме и более не находят поддержки как со стороны общественности, так и в политической сфере международных отношений. Но, несмотря на это, все же многие страны сохранили приверженность к оценке всех выгод и издержек, входящих в прямые иностранные инвестиции. Другие же напротив, открыли свои двери для иностранных инвесторов, впустив их на отечественный рынок практически сведя к минимуму возможные ограничения допуска иностранных вложений.

К проблеме дифференциации допуска иностранных инвестиций в экономику страныреципиента существуют различны подходы. Одним из оснований такого деления является уровень открытости государства в принятии решения об установлении критериев для допуска прямых инвестиций в экономику страны. Предложенная Т. Полланом классификация моделей допуска иностранного контента в экономику страны является наиболее распространенной, и включает в себя шесть основных моделей допуска:

- модель «the investment-control-model», которая подразумевает тотальный контроль над процедурой допуска иностранных инвестиций на внутренний рынок;

- модель «the positive-list-model», которая разрешает допуск к сферам экономической деятельности, названных в специальном списке, для иностранных инвестиций;

- модель «the regional-MNE-model», предоставляющая доступ инвестициям транснациональных корпораций для интенсификации собственных внутренних региональных инвестиций;

- модель «the mutual-national-treatmentmodel» представляет собой открытую возможность для допуска внутренних региональных инвестиций. Данная модель исключает только инвестиции стран третьего мира. Примером может служить Европейский Союз;

- модель «the negative-list-model», дает возможность для любых иностранных инвестиций, кроме тех, что находятся в закрытом доступе для иностранных инвесторов и названы в специальном списке секторов экономики;

Модель «the open-admission-model», которая предоставляет открытый допуск для иностранных инвестиций [5].

Незначительно отличается от предыдущей градация подходов к праву допуска на внутренний рынок иностранных инвестиций предложенная ЮНКТАД. Здесь следует выделить пять основных моделей допуска иностранного контента на отечественный рынок:

- модель «the investment-control», которая подразумевает полный контроль со стороны органов государственной власти за всеми иностранными инвестициями, входящими на внутренний рынок, с подробным анализом возможных рисков и оценкой влияния на экономику страны-реципиента;

- модель «selective liberalization», которая дает ограниченную возможность для иностранных инвесторов под контролем со стороны государства, на территории которого предполагается объект инвестирования, быть допущенными на внутренний рынок страны-реципиента и только в строго определенные сферы, входящие в «позитивный список» постпредством опреде- 
ленных соглашений;

- модель «the regional industrialization», которая дает возможность полного доступа иностранных инвестиций в соответствии с действующим национальным режимом, установленном для инвесторов из стран-членов этого регионального экономического интеграционного сообщества в целях оказания содействия эффективному воплощению программы модернизации и индустриализации;

- модель «mutual national treatment» состоит в предоставлении права допуска в полном объеме на основе национального режима рассмотрения иностранных инвестиций для всех участников инвестиционных отношений При этом, такими участниками могут выступать как как физические, так и юридические лица, имеющие специализацию в области трансграничной предпринимательской деятельности со стороны позиции стран-участников регионального экономического интеграционного сообщества, подкрепленную советующими положительными рекомендациями в этой сфере деятельности;

- модель «национальный режим с наибольшим уровнем благоприятствования», предоставляет полные права возможного допуска, базирующегося на национальном режиме или режиме наибольшей степени благоприятствования, за исключением допуска в отдельные сектора экономики, закрепленные в «негативных» списках.

В практической деятельности наиболее часто используемой моделью является модель «the investment-control», в то время как последняя модель характерна для стран, стремящихся взять курс на либерализацию режима допуска иностранного контента в сферу инвестиционной деятельности.

Из приведенного анализа предложенных моделей допуска иностранного контента на рынок страны-реципиента следует предложить следующие основные варианты инвестиционной политики государства:

Первый вариант: Для применения модели «the investment-control» требуется создание с высокой степенью надежности системы контроля «скрининга» всех входящих на внутренний рынок иностранных инвестиций.

Второй вариант: Для внедрения модели «selective liberalization», необходимо на законодательном уровне принять документы, заключающих в себе перечень отраслей, которые могут быть открыты для иностранного контента, ины- ми словами создать список с положительным набором секторов экономики для всех возможных участников.

Третий вариант: Для взятия курса на реализацию модели «the regional industrialization», необходимо выработать меры стимулирующего характера.

Четвертый вариант: В целях создания режима наибольшего благоприятствования прямых иностранных инвестиций на основе взаимного национального режима следует закрепить соответствующие правила поведения в национальном законодательстве государств, которые позволили бы претворить в жизнь двусторонние интересы от интеграции регионального значения, но при этом создать действенные механизмы, направленные на сдерживание многосторонней либерализации.

Пятый вариант: Для того, что воплотить в действие модель «национальный режим с наибольшим уровнем благоприятствования» и предоставить доступ для инвесторов из числа договаривающихся государств на основе выбора из этих двух представленных правовых режимов, следует учитывать только «негативный список» обусловленных видов деятельности, отраслевых секторов экономики.

Шестой вариант: В целях воплощения данного варианта, состоящего из комбинации моделей необходимо проанализировать их на предмет совместимости, поскольку эта комбинация не всегда может работать эффективно совместно.

Проанализированные нами варианты были ограничены в своем применении исключительно вопросом допуска иностранных инвестиций, не затрагивая при этом возможность реализации органами государственной власти политики, направленной на стимулирование выгод от прямых иностранных инвестиций или же к сведению любых рисков от результатов такой деятельности.

Подробный анализ всех вышеназванных моделей, наводит на заключение о том, что для оценки состояния государственного регулирования прямых иностранных инвестиций в Российской Федерации с наибольшей вероятностью подходит модель «the negative-list-model», базирующаяся на выделении стратегически или критически значимых секторов экономики. Важно так же учитывать то обстоятельство, что допуск иностранных инвесторов на российский рынок 
реализуется посредством учреждения изъятий ограниченного характера для иностранного контента инвесторов или инвестиционных ограничений, закрепленных в Федеральном законе «Об иностранных инвестициях в РФ». В п. 2 ст. 4 вышеназванного закона говориться о вариантах такого изъятия для иностранных инвесторов, которое согласно приведенной норме, носит ограниченный характер и допускается только в случае, если создается угроза основам конституционного строя, нравственности, здоровья, прав и законных интересов граждан, обеспечения обороны страны и безопасности государства [6]. По нашему мнению, в указанной норме на законодательном уровне закреплена не только вероятность для ограничения прав иностранных инвесторов, но и учреждение в отношении них дополнительных мер контрольноадминистративного характера. Так же хотелось бы обратить внимание, что западные концепции допуска иностранных инвестиций в большей степени находится в зависимости от таких факторов как, например, определение сущности и мотивов инвестиций, инвестиционные стимулы, которые могут быть представлены в виде формирования благоприятного климата для допуска иностранных инвестиций и создания необходимых и достаточных условия для реализации возложенных на них задач и функций.

Подводя итог вышесказанному, изучив концепции отечественной правовой доктрины и зарубежные источники в отношении допуска инвесторов на рынок страны - реципиента, в дополнение к наличествующим в юридической литературе концепциям, можем предложить собственное видение определения данного понятия: допуск иностранных инвесторов на рынок страны-реципиента - это совокупность законодательно закрепленных правил поведения, учреждающих основополагающие общие начала, включая содержание иностранных инвестиций, изъятия и ограничительного характера, процедурность урегулирования возможных споров между участниками инвестиционной деятельности, необходимые и достаточные мероприятия по контролю в соответствии с действующими мерами запретительного и ограничительного характера, и направленные на реализацию возможности иностранного инвестора осуществлять инвестиционную деятельности на территории страны - реципиента на взаимовыгодных для обеих сторон условиях.

При этом совокупность правил, норм, регламентирующих определенную сферу общественных отношений, есть не что иное как, определение правового режима. То есть, допуск прямых иностранных инвестиций, выступая одним из важнейших компонентов национального правового режима иностранного инвестора, постепенно приобретает черты особого правового режима, учреждающего особый порядок регламентации, выражающийся в наборе правовых средств, взаимодействующих между собой дозволений, запретов и мер ограничительного характера в сфере прямых иностранных инвестиций, которые в значительной степени подпадают под сферу регулирования норм административного права.

\section{Библиографический список}

1. Алексеев С.С. Восхождение к праву. Поиски и решения. 2-е изд., перераб. и доп. М.: НОРМА, 2002. С. 270.

2. Дораев М.Г. Допуск иностранных инвесторов в стратегические отрасли экономики (правовые основы)/ М.Г. Дораев.-М.: Инфотропик Медиа, 2012.-224 с.

3. Глазьев С.Ю. О некоторых мерах по укреплению экономическйо безопасности России и выводу российской экономики на траекторию опережающего развития. Доклад/ С. Ю. Глазьев.- М.: институт экономических стратегий, Русский биографический институт, 2015.; Тедтоев А.С. Государственно-правовое регулирование инвестиционной деятеллности в Российской Федерации: дис.канд. юрид. наук. Москва, 1999. С. 15. и др.

4. Пушкин А.В. Правовой режим иностранных инвестиций в Российской Федерации: Юрист, 2007.

5. Pollan. T. Legal Framework for the admission of FDL? Eleven International Publiching, 2006.

6. Федеральный закон от 9 июля 1999 г. № 160-ФЗ Об иностранных инвестициях в Российской Федерации (с изменениями и дополнениями)//Собрание законодательства Российской Федерации от 12 июля 1999 г., № 28, ст. 3493. 